\title{
Aspects of weathering and solute acquisition processes controlling chemistry of proglacial stream at Dokriani Glacier, Central Himalaya, India
}

\author{
Shipika Sundriyal ${ }^{* 1}$, Tanuj Shukla ${ }^{2}$, Rajesh Singh $^{1}$, Dwarika Prashad Dobhal $^{3}$ \\ ${ }^{1}$ National Institute of Hydrology, 247667, Roorkee \\ ${ }^{2}$ Indian Institute of Technology, Kalyanpur, 208016, Kanpur \\ ${ }^{3}$ Centre for Glaciology, Wadia Institute of Himalayan Geology, 33 GMS Road, 248001, \\ Dehradun
}

Being one of the youngest and most fragile ecosystems, the Himalaya shelters the largest. Concentration of glaciers outside the polar region. There are about 9,575 glaciers in Indian Himalaya covering an area of $37,466 \mathrm{~km}^{2}$, with an approximate storage of $2000 \mathrm{~km}^{3}$ fresh water. The region is aptly called the "Water Tower of Asia" as it provides around $8.6 \times 106 \mathrm{~m}^{3}$ of water annually and the glaciers form one of the major component of the hydrological cycle. Therefore, it is important to study the dynamics of the changes taking place in the Himalayan glaciers due to the ongoing climate change. In order to understand the effect of the climate and changes in the glaciers, it is important to analyze the water chemistry of glaciers. This analysis is one of the visible indicators that provide a fair idea about the health of the glaciers. Water sampling for major ion chemistry was performed at a proglacial and subglacial outflows from the entire ablation season. The study focuses on the characteristics and differences between chemical processes in subglacial and proglacial zone. Firstly we examine seasonal variations of the entire ablation season in relation to both subglacial and proglacial zone. Secondly, we assess the role of sulphide oxidation, carbonation, weathering processes in this system. Thirdly, we estimate the solute fluxes and the chemical denudation rate and compare these data with previous reported data and other parts of the Himalayan glacerizied basins. This study is important because this give a new insight into seasonal geochemical dynamics occurring in the glacial and proglacial environments of a highly reactive glacerizied basin.

Keywords. Himalayan Glacier, Hydrological cycle, Subglacial, Proglacial, Sulphide oxidation, Carbonation, Weathering. 